\title{
0 regramento ambiental de parcelamento do solo como instrumento para a Cidade Saudável no estado de São Paulo
}

DosSIER DE PESQUISA : CidADE SAUdÁVEL

\section{Livia Fernanda Agujaro}

Bióloga, Doutora em Saneamento e Ambiente pela Universidade Estadual de Campinas. Campinas [SP]

Brasil <liviagujaro@hotmail.com>.

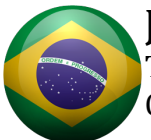

\section{Juliana Fontes Lima Collaço}

Tecnóloga em Saneamento Ambiental, Mestre em Saneamento e Ambiente pela Universidade Estadual de Campinas Campinas [SP] Brasil <juliana.cfl@gmail.com>.

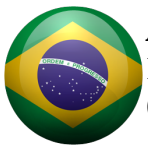

\section{Adonai Guimarães Pinto}

Engenheiro ambiental, Mestrando em Saneamento e Ambiente pela Universidade Estadual de Campinas. Campinas [SP] Brasil <adonai.pinto@gmail.com>.

\begin{abstract}
Resumo
As Áreas Verdes Urbanas, assim definidas em lei, podem trazer benefícios em termos de qualidade de vida da população pelos serviços ecossistêmicos associados. Em consonância com a Política Nacional de Promoção da Saúde cabe ao poder público apoiar o desenvolvimento de espaços de produção social e ambientes saudáveis, favoráveis ao desenvolvimento humano e ao bem-viver; contribuindo para formação de agendas de promoção da saúde. A cidade saudável deve prover qualidade ambiental a seus habitantes, com o zoneamento prevendo equipamentos urbanos que visem aos serviços ambientais e que preservem as funções ecossistêmicas do ambiente. A tendência de implantação de grandes loteamentos fechados, uma realidade frequente no Estado de São Paulo, molda a configuração espacial urbana, enclausurando áreas verdes públicas, impedindo o uso destas pela população em geral e comprometendo suas funções ambientais. Este artigo pretende criar uma reflexão sobre a realidade do licenciamento ambiental de loteamentos urbanos e aspectos legais no Estado de São Paulo que podem impactar na saúde ambiental no que se refere às áreas verdes, bem como avaliar a relação da população com estes espaços, tendo como base vivências na análise técnica para aprovação de projetos habitacionais dos autores, o que contribuirá para a construção de espaços públicos saudáveis mais participativos e integrativos.
\end{abstract}

\section{Palavras-chave}

Parcelamento do solo. Áreas verdes urbanas. Cidade saudável.

\section{The environmental requirements of land subdivision as instruments for the Healthy City in Sao Paulo State [Brazil]}

\begin{abstract}
Urban green areas, as defined by law, can bring benefits in terms of the quality of life of the population by associated ecosystem services. Consistent with the National Policy for Health Promotion, it is the responsibility of the public power to support the development of spaces for social production and healthy environments that are conductive to human development and well-being, contributing to the formation of health promotion agendas. The healthy city must provide environmental quality to its inhabitants, with zoning foreseeing urban facilities that aim at environmental services and that preserve the ecosystem functions of the environment. The tendency to implement large closed spaces, a frequent reality in the state of São Paulo, shapes the urban spatial configuration, cloistering public green areas, which prevents the use of these by the population in general and compromises their environmental functions. This article intends to create a reflection on the reality of environmental licensing of urban occupations and legal aspects in the state of São Paulo that can impact on environmental health in relation to green areas, as well as evaluate the relationship of the population to these spaces, based on experiences in the technical analysis for the approval of urban projects of the authors, which will contribute to the construction of healthier, more participatory, and integrative public spaces.
\end{abstract}

\section{Keywords}

Land subdivision. Urban green areas. Healthy city. 


\section{Introdução}

As Áreas Verdes Urbanas podem trazer benefícios em termos de qualidade de vida da população por contribuir com diversos fatores tais como mitigação da poluição do ar, regulação da umidade e da temperatura do ar, permeabilização do solo, proteção contra processos erosivos, redução dos níveis de ruídos e amenização visual da paisagem, além de servirem como áreas de lazer (Benini \& Martin, 2010). Esses ganhos ambientais assumem um papel de equilíbrio no espaço antrópico como compensação pelos efeitos da falta de arborização, da impermeabilização e de outros efeitos do processo de urbanização (Lima \& Amorim, 2006). Em consonância com isso, a Política Nacional de Promoção da Saúde (BRASIL, 2014) estabelece entre seus objetivos específicos apoiar o desenvolvimento de espaços de produção social e ambientes saudáveis, favoráveis ao desenvolvimento humano e ao bem-viver; além de definir ambientes e territórios saudáveis como referência para a formação de agendas de promoção da saúde.

A cidade saudável deve prover qualidade ambiental a seus habitantes, com seu zoneamento prevendo equipamentos urbanos que visem aos serviços ambientais e que preservem as funções ecossistêmicas do ambiente. De acordo com a Avaliação Ecossistêmica do Milênio realizada pela Organização das Nações Unidades (Millennium Ecosystem Assessment, 2005) os serviços ecossistêmicos estão fortemente ligados a componentes do bem-estar humano, podendo ser classificados nas seguintes categorias:

- Provisão - os produtos obtidos dos ecossistemas: alimentos, água doce, madeira, fibras, combustíveis;

- Regulação - processos naturais que regulam as condições ambientais: absorção de gás carbônico pela fotossíntese nas florestas; controle do clima, polinização de plantas, atenuação da incidência de doenças e pragas;

- Serviços culturais - aspectos culturais diversos: fatores estéticos e contemplativos, espiritualidade, educação e recreação;

- Suporte - contribuição para os demais serviços ecossistêmicos: ciclagem de nutrientes, formação do solo e produção primária.

A tendência de implantação de grandes loteamentos fechados, que vem se tornando uma realidade frequente no Estado de São Paulo nas últimas décadas, sendo a principal modalidade de urbanização, frequentemente está associada à construção de muros ou cercas para proteção de seus moradores de forma irregular, enclausurando áreas verdes públicas, o que impede o uso destas pela população em geral e compromete as funções ambientais destas áreas como corredores de fauna e conectividade na manutenção da biodiversidade. Essa fragmentação imprime na paisagem cenários inóspitos, que não favorecem a apropriação dos espaços públicos pela população, bem como o lazer e os benefícios à saúde decorrentes.

No ambiente urbano as questões ambientais se tornam fortes aliadas das políticas de promoção da saúde, principalmente no que se refere ao saneamento básico, porém os modelos de ordenamento urbano ainda não são devidamente considerados como fatores promotores do ambiente urbano saudável. Conforme apontado por Sperandio et al. (2016), o Estatuto da Cidade (Brasil, 2001) e a Política Nacional de Promoção da Saúde (Brasil, 2006) e sua revisão (Brasil, 2014) representam marcos regulatórios importantes que se complementam no planejamento urbano voltado à promoção de cidades saudáveis, sendo necessária a continuidade do desenvolvimento do tema de forma interdisciplinar no âmbito acadêmico para que possam ser consolidadas no Brasil as Áreas Verdes Urbanas e outras formas de espaços de promoção à saúde.

Este artigo pretende criar uma reflexão sobre aspectos dos projetos de parcelamento do solo urbano que podem impactar na saúde ambiental no que se refere às áreas verdes, bem como sobre a relação da população com esses espaços, tendo como base vivências na análise técnica para aprovação de projetos habitacionais, avaliando as contribuições na construção de espaços saudáveis.

\section{As áreas verdes no contexto dos parcelamentos de solo urbanos}

Na Avaliação Ecossistêmica do Milênio (Millennium Ecosystem Assessment, 2005) foi verificado que a demanda por paisagens naturais esteticamente agradáveis vem crescendo de acordo com o 
processo de urbanização, ao passo que houve à nível global uma queda da quantidade e qualidade das áreas disponíveis para atender a essa demanda, bem como a limitação do acesso das populações urbanas às paisagens naturais, o que pode ter efeitos prejudiciais importantes na saúde pública e no bem-estar.

Em âmbito nacional o parcelamento de solo para fins urbanos é regido pela Lei Federal no 6.766, de 19 de dezembro de 1979 (Brasil, 1979) e suas alterações, que estabelece entre os requisitos mínimos para loteamentos a existência de espaços livres de uso público proporcionais à densidade de ocupação prevista, os quais passam a integrar o domínio do Município após o registro do loteamento. Atualmente, no Estado de São Paulo, a exigibilidade de áreas verdes em loteamentos advém da Resolução no 72 de 19 de julho de 2017 da Secretaria de Estado do Meio Ambiente (São Paulo, 2017), que exige a manutenção das características naturais de permeabilidade em, no mínimo, $20 \%$ da área a ser loteada. Essas áreas permeáveis (ou verdes) têm como finalidade assegurar a infiltração das águas pluviais, a conservação da biodiversidade, a mitigação da formação de ilhas de calor e da poluição sonora e atmosférica; devendo ser revegetadas quando essa medida for tecnicamente cabível, sendo possível sua destinação parcial para implantação de equipamentos esportivos e de lazer, desde que respeitados os critérios de permeabilidade. Na legislação estadual a obrigatoriedade da destinação de áreas verdes teve início com a Resolução Conjunta da Secretaria de Estado do Meio Ambiente e do Instituto Brasileiro do Meio Ambiente e dos Recursos Naturais Renováveis de São Paulo no 02, de 12 de maio de 1994, que trata somente das áreas inseridas no bioma Mata Atlântica (São Paulo, 1994).

Complementam as áreas verdes as áreas de preservação permanente definidas pela Lei Federal no 12.651 de 25 de maio de 2012 (Brasil, 2012) e suas alterações, as quais incidem sobre os recursos hídricos superficiais, áreas com declividades elevadas, etc., sendo destinadas como áreas verdes nos projetos de loteamentos. A definição dos espaços livres de uso público em loteamentos, tais como áreas verdes e sistemas de lazer, também está sujeita às exigências e critérios urbanísticos estabelecidos na legislação municipal. Benini e Martin (2010) apontam a necessidade do alinhamento dos conceitos de áreas verdes com a legislação urbanística e ambiental, de modo a possibilitar uma leitura menos subjetiva desses espaços, propondo o seguinte conceito: [...]

[...] área verde pública é todo espaço livre (área verde/lazer) que foi afetado como de uso comum e que apresente algum tipo de vegetação (espontânea ou plantada), que possa contribuir em termos ambientais (fotossíntese, evapotranspiração, sombreamento, permeabilidade, conservação da biodiversidade e mitigue os efeitos da poluição sonora e atmosférica) e que também seja utilizado com objetivos sociais, ecológicos, científicos ou culturais.

Nesses e em outros diplomas legais relacionados ao licenciamento de empreendimentos habitacionais, verifica-se a ausência de mecanismos de participação da população no processo de planejamento e implantação dos espaços urbanos, com exceção do caso de empreendimentos de grande porte ou em locais com restrições específicas, quando pode ser necessária a realização de audiências públicas como parte dos estudos de impacto ambiental. Em que pese a diretriz de participação da população na formulação, execução e acompanhamento de planos, programas e projetos de desenvolvimento urbano constante no Estatuo da Cidade (Brasil, 2001), na prática na maior parte dos empreendimentos não se percebe a presença ativa desses elementos de participação popular, mesmo quando há na localidade conselho municipal de meio ambiente.

A crescente saturação dos grandes centros urbanos, juntamente com a pressão do mercado imobiliário, faz com que os perímetros urbanos avancem sobre áreas com características rurais e menos propícias à ocupação urbana, onde pode haver remanescentes florestais, unidades de conservação, recursos hídricos e suas áreas de preservação permanente, topografia irregular ou com declividades acentuadas, entre outros elementos. Esse contexto resulta na criação de interfaces conflituosas entre usos do solo urbanos e rurais, nas quais se inserem as áreas verdes e sistemas de lazer dos loteamentos. O estrangulamento dos remanescentes florestais e das matas ciliares, que nas áreas urbanas ficam limitadas às áreas verdes de loteamentos e áreas de preservação permanente exigidas na legislação (eventualmente complementadas por parques e unidades de conservação), impede a existência de zonas de transição, que poderiam atenuar os 
efeitos da mudança brusca da paisagem antropizada para a natural. Cabe observar que consta como diretriz da política urbana no Estatuto da Cidade (Brasil, 2001) a ordenação e controle do uso do solo, de forma a evitar a proximidade de usos incompatíveis ou inconvenientes, a deterioração das áreas urbanizadas e a poluição e a degradação ambiental.

Os atuais modelos de ocupação do território trouxeram novos desafios em termos de saúde pública e qualidade ambiental, que demandam novas estratégias para urbanistas, poder público e empreendedores visando às premissas da cidade saudável. 0 processo de conurbação das cidades e a alta demanda por isolamento em parcelamentos de solo fechados aceleraram a conversão de glebas rurais em áreas urbanas. Entretanto, as ilhas urbanas construídas no ambiente rural acarretam novas vias de circulação de vetores e a sinantropização dos animais silvestres. 0 maior convívio com os animais silvestres até então visto apenas positivamente do ponto de vista contemplativo, esconde os perigos à saúde pública, explicitados por exemplo com os recentes casos de febre maculosa e febre amarela silvestre chegando aos aglomerados urbanos.

Bernardini (2018) descreve a evolução do planejamento da expansão urbana na Região Metropolitana de Campinas [SP], que combinou dispersão territorial e segregação socioespacial, tendo nas últimas décadas o loteamento fechado e o condomínio horizontal como principais tipologias. Segundo o autor, mesmo em casos onde já havia plano diretor municipal, as expansões urbanas foram tratadas de maneira pontual nas legislações municipais, não seguindo diretrizes claras, o que resultou, em alguns casos, na criação de áreas urbanas descontínuas dispostas como ilhas sobre as áreas rurais. Na região de Campinas também foram verificadas pelo autor situações em que os municípios ampliaram seus perímetros urbanos de modo a praticamente coincidir com os próprios limites territoriais, extinguindo a figura das zonas rurais.

Há de se reconhecer a importância das exigências legais referentes à implantação de áreas verdes e sistemas de lazer, visto que delas advém a maior parte dos espaços livres de uso público criados durante o processo de urbanização das últimas décadas. No entanto, não é difícil se deparar com situações em que a destinação prevista para essas áreas não corresponde aos anseios da população residente. A presença de vegetação de porte florestal pode representar aos moradores riscos em termos da presença de animais peçonhentos e vetores de doenças, ou por fornecer esconderijos a criminosos, o que muitas vezes é respondido com a construção de muros ou cercas em condições irregulares. Há ainda os casos em que os moradores decidem por se apropriar das áreas verdes e sistemas de lazer para diversas finalidades, que incluem estacionamento, edificações, criação de animais, hortas, áreas de lazer particulares, etc. Essa utilização, a princípio, irregular dos espaços livres públicos é percebida com maior frequência em áreas ocupadas por população menos favorecidas, onde os lotes apresentam menor dimensão e maior densidade de ocupação, gerando a demanda pela ocupação desses espaços para que sejam atendidas as necessidades dos moradores.

Esse descompasso entre as previsões legais e as condições reais de uso dos espaços livres públicos com frequência resulta em condições de abandono dessas áreas, que são tomadas por vegetação exótica invasora e usadas para disposição de resíduos sólidos, além de conflitos entre o poder público e a população que dificilmente serão solucionados. Em uma avaliação das áreas verdes do município de Osvaldo Cruz [SP], Lima e Amorim (2006) verificaram que muitas delas são constituídas de sobras de loteamentos, não tendo características adequadas para sua finalidade como espaço livre de uso público, havendo ainda fração significativa de áreas que nunca foram concretizadas como áreas verdes arborizadas ou espaços de uso público, se tornando terrenos baldios.

\section{Conclusão}

As áreas verdes e sistemas de lazer provenientes de projetos de loteamentos apresentam potencial como espaços para construção de cidades saudáveis, porém verifica-se uma realidade de baixo aproveitamento desses espaços livres de uso público urbanos. Devem ser avaliadas formas de melhorar a efetividade das áreas verdes como fatores de promoção da saúde, que possam tanto cumprir as funções ecológicas quanto atender às necessidades da população, sendo a consideração da população no processo de planejamento um requisito para o atingimento dos objetivos das áreas verdes urbanas. É necessária uma reflexão acerca da criação de formas para a participação social no processo de urbanização, com a capacitação de gestores públicos para a construção de 
um diálogo mais aberto com a população, de modo a se formular critérios urbanísticos territoriais mais específicos que vão além das macrodiretrizes estabelecidas nos planos diretores, aproximando os propositores dos projetos urbanísticos das demandas da sociedade.

A expansão sobre vazios urbanos e áreas rurais pode criar interfaces conflituosas entre os espaços antrópico e natural, que muitas vezes coincidem com as áreas verdes de loteamentos, podendo haver inconvenientes à população e impactos negativos aos ecossistemas. Assim, na concepção dos zoneamentos e demais instrumentos de planejamento territorial municipais e regionais devem ser previstos mecanismos para mitigação dos efeitos dessas alterações bruscas na paisagem urbana, mesmo que isso signifique a contenção dos processos de crescimento das cidades.

Os serviços ecossistêmicos devem estar presentes na concepção das áreas verdes urbanas propiciando o bem-estar humano e a promoção da saúde, na forma de produção de alimentos com a implantação de hortas comunitárias, plantio de espécies frutíferas e medicinais, conforto térmico e regulação do clima, aspectos estéticos, recreacionais e educacionais, e que sejam de livre acesso à população que irá habitar seu entorno.

No que se refere à legislação, há que se preencher a lacuna existente entre os diplomas legais que tratam do meio ambiente e aqueles que abordam o bem-estar social e a promoção da saúde, promovendo a integração entre esses temas e propiciando uma estrutura de planejamento urbano que harmonize a interface entre os espaços antrópicos e naturais. No caso da legislação que estabelece os requisitos de áreas verdes para loteamentos, que é de cunho ambiental, fica clara a falta de diretrizes para utilização das áreas verdes e sistemas de lazer como espaços de vivência da população, havendo maior tendência à promoção da restauração florestal dessas áreas como espaços naturais, pouco se ocupando das mesmas como espaços de vivência e contato da população com o bem natural de forma integral em todas suas potencialidades. Além disso é importante que a academia incorpore os instrumentos legais nos estudos para a concepção de novas formas de abordagem do planejamento urbano das cidades, que levem em conta a multiplicidade dos fatores envolvidos para que sejam efetivamente aplicáveis.

Como decorrência desta reflexão vislumbram-se oportunidades de pesquisas acadêmicas para aprofundar o conhecimento e subsidiar a construção de arcabouços conceituais que integrem o planejamento urbano com os fatores ambientais para tornar os espaços urbanos mais saudáveis e sustentáveis.

\section{Referencias}

Benini, S. M., \& Martin, E. S. (2010). Decifrando as áreas verdes públicas. Formação, 2(17), 63-80. Presidente Prudente [SP].

Bernardini, S. P. (2018). O planejamento da expansão urbana na interface com a urbanização dispersa: uma análise sobre a região metropolitana de Campinas (1970-2006). Urbe. Revista Brasileira de Gestão Urbana, 10(1), 175-185. Curitiba [PR].

Brasil (1979). Lei $n^{o}$ 6.766, de 19 de dezembro de 1979. Dispõe sobre o Parcelamento do Solo Urbano. Recuperado de: <http://www.planalto.gov.br/ccivil_03/LEIS/L6766.htm>.

Brasil (2001). Lei $n^{\circ}$ 10.257, de 10 de julho de 2001. Estabelece diretrizes gerais da política urbana. Disponível em: <http://www.planalto.gov.br/ccivil_03/leis/LEIS_2001/L10257.htm>.

Brasil, Ministério da Saúde (2006). Política Nacional de Promoção da Saúde. Brasília: Ministério da Saúde, 2006. 60 p. Recuperado de: <http://bvsms.saude.gov.br/bvs/publicacoes/politica_promocao_saude.pdf>.

Brasil (2012). Lei no 12.651, de 25 de maio de 2012. Dispõe sobre a proteção da vegetação nativa. Recuperado de: <http://www.planalto.gov.br/ccivil_03/_ato2011-2014/2012/lei/l12651.htm>.

Brasil, Ministério da Saúde (2014). Portaria no 2.466, de 11 de novembro de 2014. Redefine a Política Nacional de Promoção da Saúde. Recuperado de: <http://bvsms.saude.gov.br/bvs/saudelegis/gm/2014/ prt2446_11_11_2014.html>. 
Lima, V., \& Amorim, M. C. C. T. (2006). A importância das áreas verdes para a qualidade ambiental das cidades. Formação, 1(13), 139-165. Presidente Prudente [SP].

Millennium Ecosystem Assessment (2005). Ecosystems and Human Well-being: Synthesis. Washington: Island Press, $137 \mathrm{p}$.

São Paulo, Secretaria de Estado do Meio Ambiente, \& Brasil, MMA, Instituto Brasileiro do Meio Ambiente e dos Recursos Naturais Renováveis (1994). Resolução Conjunta no 02, de 12 de maio de 1994. Regulamenta o corte, a exploração e a supressão de vegetação da Mata Atlântica no Estado de São Paulo. Recuperado de : <http://arquivos.ambiente.sp.gov.br/resolucao/1994/1994_Res_Conjunta02.pdf>.

São Paulo, Secretaria de Estado do Meio Ambiente (2017). Resolução no 72, de 18 de julho de 2017. Dispõe sobre os procedimentos para análise dos pedidos de supressão de vegetação nativa para parcelamento do solo, condomínios ou qualquer edificação em área urbana. Recuperado de: <https:// www.ambiente.sp.gov.br/legislacao/resolucoes-sma/resolucao-sma-72-2017/>.

Sperandio, A. M. G., Francisco Filho, L. L., \& Mattos, T. P. (2016). Política de promoção da saúde e planejamento urbano: articulações para o desenvolvimento da cidade saudável. Ciência \& Saúde Coletiva, 21(6), 1931-1937. Rio de Janeiro [RJ]. 